\title{
CUBRIMIENTO RADICULAR DE UNA RECESIÓN GINGIVAL LINGUAL: REPORTE DE UN CASO.
}

\author{
Carlos Martín Ardila Medina \\ Odontólogo, U. Santo Tomás. Especialista en Prótesis Periodontal C. E. S. \\ Docente U. de Antioquia y U. Cooperativa de Colombia.
}

Autor responsable de correspondencia: Dr. Carlos Martín Ardila Medina

Correo electrónico: abejamar@hotmail.com

\begin{abstract}
RESUMEN
Se reporta un caso clínico en el que se usó una técnica para obtener cubrimiento de recesiones gingivales linguales. La técnica involucra elevar un colgajo pediculado lingual de espesor parcial desplazado coronalmente, posicionando además un injerto subepitelial de tejido conectivo debajo del colgajo y sobre la recesión. Se obtuvieron cantidades clínicamente significativas de cubrimiento radicular (75\%) y ganancia de inserción $(5 \mathrm{~mm})$. Es posible cubrir las recesiones gingivales linguales combinando injertos subepiteliales de tejido conectivo y colgajos parciales pediculados linguales desplazados coronalmente. [Ardila CM. Cubrimiento radicular de una recesión gingival lingual: Reporte de un caso. Ustasalud Odontología 2003; 2: 119 - 122]
\end{abstract}

PAL.ABRAS CL.AVE: Recesión gingival, injertos, colgajos quirúrgicos.

Root coverage of a lingual recession: A case report.

\begin{abstract}
To describe a technique to cover a lingual recession. The technique involved elevating a coronally advanced partial thickness lingual pedicle flap and placing a subepithelial connective tissue graft beneath the flap and over the recession defect. Clinically significant amounts of root coverage were obtained (75\%) and attachment gain was $5 \mathrm{~mm}$. Root coverage of a lingual recession can be obtained with a subepithelial connective tissue graft placed under a coronally advanced partial thickness lingual pedicle flap.
\end{abstract}

KEY WORDS: Gingival recession, graft, surgical flaps.

Recibido para publicación: 15 de septiembre de 2003. Aceptado para publicación: 4 de noviembre de 2003.

\section{INTRODUCCIÓN}

Cubrir recesiones gingivales se ha convertido en una parte importante de la terapia periodontal. Los pacientes requieren $\mathrm{y}$, a veces demandan, procedimientos para cubrir recesiones. Dichos procedimientos pueden ser llevados a cabo por razones funcionales o estéticas.

Varias técnicas se han desarrollado para obtener el cubrimiento de la superficie radicular. Estas técnicas incluyen el uso de injertos pediculados, injertos gingivales libres, injertos subepiteliales de tejido conectivo combinado con colgajos pediculados, regeneración tisular guia- da, y matriz dérmica acelular. ${ }^{1,2}$ Estas técnicas han mostrado ser efectivas en diferentes estudios clínicos con buenos resultados funcionales, estéticos y de predecibilidad. ${ }^{1-3}$

La mayoría de estudios que examinan las diferentes técnicas para el cubrimiento de las recesiones no reportan algún tratamiento para las recesiones gingivales linguales. Existen varias razones que pueden complicar su tratamiento: probablemente el factor mas importante es sí una recesión gingival lingual necesita ser trata- 
da, no hay implicaciones estéticas en esta zona, hay factores que hacen que la técnica sea dificil como el acceso quirúrgico, dificultando a su vez la reposición coronal o lateral de un colgajo pediculado y el cubrimiento de un injerto subepitelial. La protección del área con relación al trauma es más dificil de controlar, durante el periodo de cicatrización, que cuando se tratan las recesiones vestibulares. A pesar de estas limitaciones, hay situaciones donde el tratamiento de las recesiones linguales puede estar indicado. Este es el reporte de un caso que presenta el tratamiento de una recesión lingual con una técnica combinada de injerto subepitelial de tejido conectivo y un colgajo pediculado desplazado coronalmente, una modificación de la técnica descrita por Langer y Langer. ${ }^{4}$

\section{Reporte del caso}

Paciente de sexo femenino de 65 años de edad referida para tratamiento de una recesión lingual Clase II de Miller, ${ }^{5}$ localizada a nivel del 42.

La paciente se encontraba en buen estado de salud y sin ninguna contraindicación para terapia quirúrgica periodontal. No fumadora. En su última cita de mantenimiento, su odontólogo general observó que la recesión estaba de mayor tamaño y decidió remitirla para tratamiento.

Al examen periodontal no se encontró en ningún diente profundidad de surco mayor de $3 \mathrm{~mm}$. Sólo existía sangrado al sondaje en la superficie lingual del 42 y las medidas de higiene oral de la paciente eran buenas, con un índice de placa bacteriana (PI) de Silness y Loe del 10\%.6 La paciente reportaba sensibilidad térmica en el área.

La profundidad de la recesión era de $4 \mathrm{~mm}$, la profundidad de sondaje en la zona de la recesión fue de $3 \mathrm{~mm}$. La pérdida de inserción fue de $7 \mathrm{~mm}$ (Tabla 1). Se observó

Tabla 1. Pérdida de inserción.

\begin{tabular}{|c|c|c|}
\hline & INICIAL & 6MESES \\
\hline Margen gingival & $0-40$ & $\begin{array}{lll}0 & -1 & 0\end{array}$ \\
\hline Surco gingival & 333 & $\begin{array}{lll}1 & 1 & 1\end{array}$ \\
\hline Nivel de Inserción & 373 & $\begin{array}{lll}1 & 2 & 1\end{array}$ \\
\hline
\end{tabular}

perdida leve de la papila distal, presencia de placa bacteriana a lo largo del margen gingival lingual del $42 \mathrm{y}$ no existía abrasión a ese nivel (Figuras 1 y 2).

Se decidió tratar el defecto combinando un injerto subepitelial de tejido conectivo y un colgajo pediculado desplazado coronalmente para cubrirlo. Se tomaron las fotografías preoperatorias (Figura 2) y la paciente leyó y firmó el consentimiento informado.

Se anestesió infiltrativa y localmente el área, se realizó alisado radicular. Se hizo una incisión intrasulcular lingual en 41 y 42 . Se realizaron incisiones verticales en mesial y distal del 42 conservando las papilas en el colgajo dividido. Se obtuvo un injerto subepitelial de tejido conectivo del lado derecho del paladar, como se describió previamente, ${ }^{4}$ el cual fue suturado a periostio sobre la recesión y ubicado por debajo del colgajo de espesor parcial. Se utilizó una sutura atraumática 4-0 para estabilizar el injerto.

El colgajo de espesor parcial se desplazó coronalmente para cubrir el injerto y se suturó con sutura atraumática 4-0 coronal y lateral al colgajo para aproximar sus bordes a los tejidos periodontales adyacentes. Se colocó apósito quirúrgico y se premedicó a la paciente con analgésicos y enjuagues con clorhexidina durante dos semanas; se aconsejó la aplicación de hielo las primeras 24 horas, además de las medidas postquirúrgicas protocolarias. No se recetaron antibióticos.

El apósito fue removido una semana después de la cirugía y se eliminó la placa bacteriana presente. El cubrimiento de la recesión era casi del 100\% y se observó viabilidad del colgajo e injerto.

La paciente fue instruida para limpiar el área con cepillo unipenacho y evitar alimentos duros en el área intervenida. El área fue reevaluada semanalmente durante seis semanas (Figura 3), se realizó control de placa (PI) en cada sesión. Se evaluó posteriormente a los tres meses (Figura 4) y seis meses registrándose las medidas clínicas pertinentes (Figuras 5).

La recesión gingival era de $1 \mathrm{~mm}$ y la profundidad de sondaje de $1 \mathrm{~mm}$ representando un cubrimiento radicular de $3 \mathrm{~mm}$ y una ganancia de inserción de $5 \mathrm{~mm}$ (Figura 4). La sensibilidad térmica disminuyó notablemente y el tejido alrededor de la antigua recesión se encontraba firmemente adherido. 


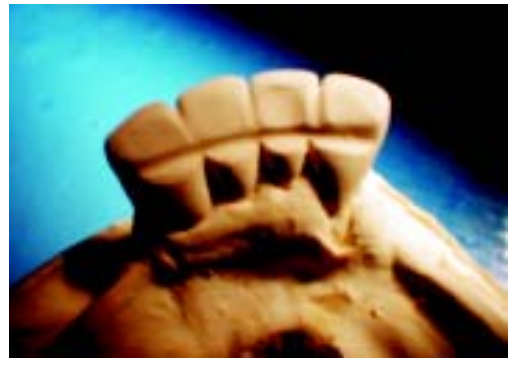

Figura 1. Modelo, preoperatorio.

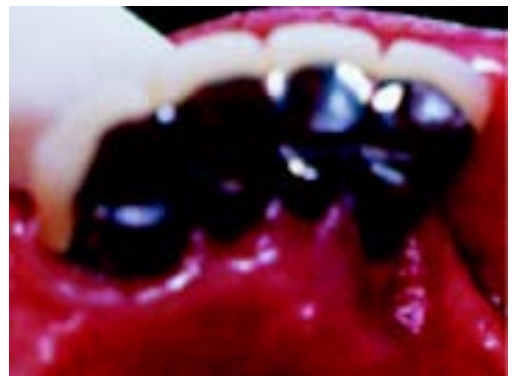

Figura 2. Apariencia preoperatorio.

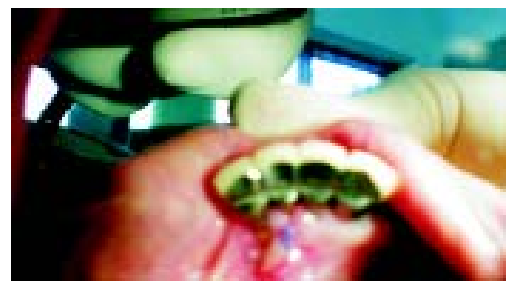

Figura 3. Reevaluación de la zona semanalmente por seis semanas.

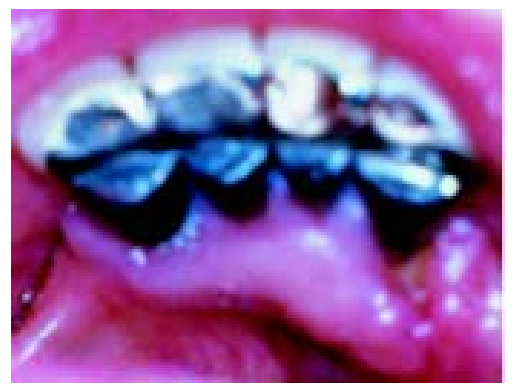

Figura 4. Control posquirúrgico a los tres meses.

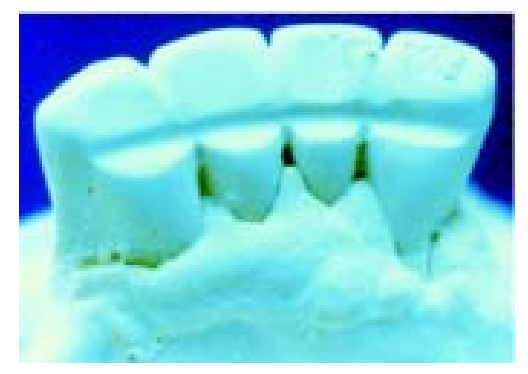

Figura 5. Modelo, control posquirúrgico a los seis meses.

\section{DISCUSIÓN}

Existen muchos estudios clínicos que han probado que la predecibilidad estética para cubrir recesiones radiculares es un objetivo alcanzable, sin embargo, pocos han sido reportados para mostrar cubrimiento de recesiones gingivales linguales.

En este caso clínico se obtuvo un cubrimiento significativo pero no completo de la recesión lingual, a pesar de ello los $3 \mathrm{~mm}$ de cubrimiento (75\%) y los $5 \mathrm{~mm}$ de ganancia de inserción fueron clínicamente valiosos. Este resultado puede ser juzgado como un éxito clínico.

Los resultados parecen ser mejores entre la primera y la segunda semana postoperatoria que en la evaluación final a los seis meses. La razón para la reducción de la cantidad de cubrimiento inicial es desconocida, pero pueden existir diferentes explicaciones. El trauma del área puede ser una de ellas, puede ocurrir con la masticación, la ubicación tan cercana a la lengua, esfuerzos en la higiene oral. A pesar de la pérdida de cubrimiento la paciente y el clínico estuvieron satisfechos con los resultados.

La histología del resultado es desconocida pues para obtener esta información se requiere la remoción de una sección en bloque y no era uno de los objetivos a lograr con el procedimiento.

Con base en los resultados de Pasquinelli, Harris, Bruno y Bowers, existe la posibilidad de que alguna regeneración haya ocurrido. Clínicamente, el área se encontraba saludable, el surco gingival en la zona presentó profundidad de sondaje de $1 \mathrm{~mm}$ con ausencia de sangrado y un tejido gingival firmemente adherido. ${ }^{7-9}$

Los resultados de este caso clínico pueden ser comparados con otros reportes para cubrir recesiones. En 1996 una revisión de literatura sobre terapia mucogingival encontró un promedio de cubrimiento del $89.3 \%$ para estudios clínicos usando injertos de tejido conectivo. ${ }^{1} \mathrm{El}$ uso de injertos de tejido conectivo combinados con colgajos pediculados posicionados coronalmente, ${ }^{4,10,11}$ pediculados posicionados lateralmente, ${ }^{12}$ doblemente pediculados, ${ }^{12-16}$ colgajo en bolsillo, ${ }^{17-19}$ y la técnica de tunelización, ${ }^{20,21}$ han mostrado resultados predecibles y estéticos en múltiples estudios clínicos. Se requieren estudios futuros para evaluar la predicibilidad de cubrimiento radicular en el caso de recesiones linguales. 
Técnicamente, el procedimiento utilizado en este caso clínico es más difícil de ejecutar que cuando se realiza en un área vestibular, el acceso a la región lingual es difícil y la manipulación de los tejidos en la zona es más complicada y dificulta la cirugía.

En este estudio podría ser considerado proteger el área quirúrgica por más de una semana, cambiando el apósito, con el fin de proteger el área por más tiempo lo cual podría mejorar los resultados.

Las indicaciones para cubrir recesiones gingivales linguales pueden ser limitadas, no existen por ejemplo demandas estéticas que exijan su tratamiento, sin embargo hay situaciones donde el procedimiento es deseable como en el caso de disminuir la sensibilidad dentinal, tratar o prevenir caries radicular, eliminar la acumulación de placa bacteriana y restablecer el contorno gingival normal. La técnica utilizada en este caso produjo un buen resultado clínico y debe ser considerada para el tratamiento de recesiones gingivales linguales.

\section{BIBLIOGRAFÍA}

1. Wennstrom J. Mucogingival therapy. Ann Periodontol 1996; 1: 671 701.

2. Harris RJ. A comparative study of root coverage obtained with an acellular dermal matrix versus a connective tissue graft: The results of 107 recession defects in 50 consecutively treated patients. Int J Periodontics Restorative Dent 2000; 20: 51 - 59.

3. Bruno J. Connective tissue graft technique assuring wide root coverage. Int J Periodontics Restorative Dent 1994; 14: 127 - 137.

4. Langer B, Langer L. Subepithelial connective tissue graft technique for root coverage. J Periodontol 1985; 56: 715 - 720.

5. Miller PD. A classification of marginal tissue recession. Int J Periodontics Restorative Dent 1985; 5: 8 - 13.

6. Silness J, Löe H. Periodontal disease in pregnancy. Acta Odontol Scand 1964; 22: 121 - 135.

7. Pasquinelli KL. The histology of new attachment utilizing a thick autogenous soft tissue graft in an area of deep recession: A case report. Int J Periodontics Restorative Dent 1995; 15: 248 - 257.

8. Harris RJ. Successful root coverage: A human histological evaluation of a case. Int J Periodontics Restorative Dent 1999; 19: 439 - 447.

9. Bruno JF, Bowers GM. Histology of human biopsy section following the placement of a subepitellial connective tissue graft. Int J Periodontics Restorative Dent 2000; 20: 225 - 231.
10. Bouchard P, Etienne D, Ouhayon JP, Nilveus R. Subepitellial connective tissue grafts in the treatment of gingival recessions. A comparative study of 2 procedures. J Periodontol 1994; 65: 929 - 936.

11. Bouchard P, Nilveus R, Etienne D. Clinical evaluation of tetracycline $\mathrm{HCl}$ conditioning in the treatment of gingival recession. A comparative study. J Periodontol 1997; 68: 262 - 269.

12. Nelson SW. The subpedicle connective tissue graft. A bilaminar reconstructive procedure for coverage of denuded root surfaces. J Periodontol 1987; 58: 95 - 102.

13. Borghetti A, Louise F. Controlled clinical evaluation of the subpedicle connective tissue graft for the coverage of gingival recession. J Periodontol 1994; 65: 1107 - 1112.

14. Harris RJ. The connective tissue and partial thickness double pedicle graft: A predictable method of obtaining root coverage. J Periodontol 1992; 63: 447 - 486.

15. Harris RJ. Creeping attachment associated with the connective tissue graft with partial thickness double pedicle graft. J Periodontol 1997; 68: 890 - 899.

16. Harris RJ. A comparative study of root coverage obtained with guided tissue regeneration utilizing a bioabsorbable membrane versus the connective tissue with partial thickness double pedicle graft. J Periodontol 1997:68: 779 - 790.

17. Jahnke PV, Sandifer JB, Gher ME, Gray JL, Richardson AC. Thick free gingival and connective tissue autografts for root coverage. J Periodontol 1993; 64: 315 - 322.

18. Raetzke PB. Covering localized areas of root exposure employing the envelope technique. J Periodontol 1985; 56: 397 - 402.

19. Muller HP, Eger T, Schorb A. Gingival dimensions after root coverage with free connective tissue grafts. J Clin Periodontol 1998; 25: 424 - 430.

20. Allen AL. Use of the supraperiosteal envelope in soft tissue grafting for root coverage. I. Rationale and technique. Int J Periodontics Restorative Dent 1994; 14: 216 - 227.

21. Allen AL. Use of the supraperiosteal envelope in soft tissue grafting for root coverage. II. Clinical results. Int J Periodontics Restorative Dent 1994; 14: 302 - 315. 